\title{
VAMPIRISMO: DRÁCULA Y LA LÓGICA CINEMATOGRÁFICA
}

\section{VAMPIRISM: DRACULA AND THE LOGIC OF CINEMA \\ Loreto GÓMEZ LÓPEZ-QUIÑONES}

\author{
Universidad de Granada \\ loreto.golopez@gmail.com
}

Resumen: Nuestro propósito es analizar las relaciones entre el mito de Drácula y la propia esencia de Séptimo Arte a través de ocho puntos de conexión: la vampirización, la oscuridad, el carácter mítico, la vida eterna, el carácter colectivo, el viaje en el tiempo y en el espacio, la misoginia y las innovaciones técnicas. Inspirándonos en la terminología de Umberto Eco, pretendemos demostrar que el fenómeno vampírico puede ser visto como una metáfora epistemológica del cinematográfico y que, a su vez, el cine mismo se reapropia y explota dicha metáfora, haciendo de la figura vampírica una de sus más relevantes tradiciones.

Abstract: In this article we aim at analyzing the relation between the myth of Dracula and the cinematographic event through eight main aspects: bleed dry, darkness, the myth, everlasting life, collective nature, the possibility to travel through time and space, misogyny and technical innovations. Borrowing Umberto Eco's terminology and through these 
eight aspects, we will develop the argument that vampirism can be understood as an epistemological metaphor of the cinematographic event. Cinema, at the same time, uses this metaphor making the best of this vampiric figure and turning it into one of its most important genres and cinema traditions.

Palabras clave: Drácula. Vampiro. Cine. Mito. Metáfora epistemológica.

Key words: Dracula. Vampire. Cinema. Myth. Epistemological metaphor.

\section{INTRODUCCIÓN}

Muchos han sido los trabajos que, desde una $u$ otra perspectiva, han abordado el mito que afianzó la novela del irlandés Bram Stoker. Los distintos estudios del Drácula de Bram Stoker han explicado esta popularidad desde muy diferentes perspectivas: psicológica, marxista, sociológica, feminista, transexual, gótica, histórica, arquetípica, etc. En su ya clásico libro Reading the Vampire, Ken Gelder (1994) elabora una recopilación de todos estos interesantes acercamientos.

En los últimos años, hemos asistido a una proliferación e intensificación del entrecruzamiento de la cultura audiovisual y el mito del vampiro que no ha hecho sino fortalecerse. Ejemplos claros de esto son las series televisivas True Blood (2008) y The Vampire diaries (2009), las sagas cinematográficas como Crepúsculo (2008) o Underworld (2003) y películas tan originales como Let the right one in (2008) o su versión americana Let me in (2010).

Nuestro propósito es el de aclarar cómo la relación entre este gran mito universal y el cinematógrafo va más allá de las adaptaciones e interpretaciones. Sería difícil abordar un estudio de Drácula sin tener en cuenta sus diversas adaptaciones cinematográficas, ya que la participación del cine en la formación del mito del vampiro ha sido definitiva. No obstante, las estrechas relaciones existentes entre el conde Drácula y el Séptimo Arte superan y trascienden el mero estudio de la adaptaciones. Existen, desde nuestro punto de vista, una serie de conexiones o concomitancias entre el mito de Drácula y la propia esencia del cine que vamos a analizar a lo largo de este estudio.

Hay un término que Umberto Eco introduce en Obra abierta, «metáfora espistemológica», que puede ser bastante útil para mi argumentación y para el tipo de relación que postulo entre el fenómeno vampírico y el hecho cinematográfico. En un momento determinado de su famoso ensayo, Eco afirma que: 
toda forma artística puede muy bien verse, sino como sustituto del conocimiento científico, como metáfora epistemológica; es decir, en cada siglo, el modo de estructurar las formas del arte refleja — a guisa de semejanza, de metaforización, de apunte de resolución del concepto en figura- el modo como la ciencia o, sin más, la cultura de la época ven la realidad (Eco, 1992: 40).

Es evidente que Umberto Eco liga estrechamente el concepto de metáfora epistemológica a una forma de conocer y comprender en una época determinada. Ahora bien, dado el objetivo de nuestro ensayo, desearía re-articular este concepto para proponer la figura del vampiro como una suerte de metáfora epistemológica que explica cómo funciona todo un género artístico: el cine. El giro de tuerca en este caso vendría provocado por el hecho de que esta metáfora es a su vez reapropiada y proyectada por el propio género cinematográfico. En otros términos, este ensayo propone que el fenómeno vampírico puede ser visto como una metáfora epistemológica del cinematográfico y que, a su vez, el cine mismo se reapropia y explota dicha metáfora, haciendo de la figura vampírica una de sus más relevantes tradiciones.

Una vez aclarados estos primeros planteamientos, pasaremos a analizar los ocho aspectos que hemos establecido como puntos de conexión entre Drácula y el cine.

\section{VAMPIRIZACIÓN}

El cine y Drácula vampirizan. Ambos vampirizan tanto la cultura y la historia como el alma y la vida de personas. Drácula es un no-muerto que ha conseguido «vivir» a lo largo de los siglos. De manera que ante sus ojos, han caído imperios, se han levantado países, se han descubierto continentes, se han producido revoluciones, cataclismos y convulsiones. Drácula ha visto pasar la historia y, sin embargo, no participa de ella. El conde, recluido en su viejo castillo de Transilvania, parece permanecer al margen de todos estos acontecimientos. El tiempo se ha parado en torno a él. Incluso en Transilvania parece no avanzar la historia.

Sin embargo, el hecho de que Drácula no participe en el curso de la historia y no permita que ningún cambio se introduzca, ni en su persona ni en su morada, no significa que no la perciba ni la asimile. De hecho, vampiriza toda la información que recibe. Drácula ha sido testigo de cambios fundamentales en la ideología y en la concepción del mundo, en las costumbres, en las construcciones arquitectónicas, en los hogares, en el vestuario o en 
las ciudades. No permite que ninguno de estos cambios penetre en su hogar, pero los observa detenidamente y, llegado el momento, sabe hacer un uso útil y productivo de ellos.

De hecho, en la novela de Bram Stoker, el personaje de Jonathan Harker se sorprende, durante su estancia en el castillo de Drácula, de la gran cultura que posee el conde. Aunque nunca ha estado en Inglaterra habla un inglés extremadamente correcto y sus conocimientos culturales y geográficos de este país son sorprendentemente amplios y profundos. Drácula parece dominar cualquier tema: asuntos legales, costumbres, modas, geografía o historia,... Nada parece escapársele a este monstruo vampirizador. En realidad, Jonathan Harker empieza a ser vampirizado mucho antes de que las vampiresas que habitan en el castillo de Drácula intenten succionarle la sangre; Harker comienza a ser vampirizado durante las primeras veladas que pasa conversando con el conde Drácula en Transilvania, en las que este procura obtener de aquél toda la información posible que le pueda ser de utilidad a la hora de establecerse en Inglaterra. Así, Drácula hace que Harker se vea obligado a mantenerse despierto toda la noche satisfaciendo al conde en todas sus curiosidades.

En lo que se refiere al cine, su relación con la cultura es muy similar a la que venimos explicando. El cine es y ha sido una máquina capaz de captar todos los cambios culturales, vitales e históricos para después devolverlos en forma de imágenes. El invento del cinematógrafo, por otra parte, ha sido el resultado de una acumulación de otras artes y técnicas que, en su unión, han dado lugar al nacimiento del Séptimo Arte. El invento de esta máquina no habría sido posible sin sus precedentes técnicos: las sombras chinescas, la cámara oscura, la linterna mágica, el daguerrotipo, el Tahumatrope, el plenakistiscope, el zoótropo, el calotipo, el kinetoscopio, el praxinoscopio, etc. El cine vampiriza todos estos artilugios. Asume, incorpora, utiliza, perfecciona y mezcla las aportaciones de estos inventos para lograr un objetivo parecido: el movimiento de las imágenes; aunque persiguiendo en su recorrido una meta más alta: presentar su representación o ficción con la apariencia de la realidad misma.

También a lo largo de la historia del cine, este ha dado muestras de su enorme capacidad para vampirizar otras artes: la pintura, la música, la fotografía, la arquitectura, las artes plásticas, el teatro, el mimo, la literatura, la danza, etc. se dan cita en el cine para unirse armoniosamente en este joven y vampirizador arte. El cine recoge una galería de lugares, personajes, historias, acontecimientos, y nos da noticia del arte, la filosofía, la forma de 
vestir y pensar en cada época. A través del cine, entramos en contacto con nuestra prehistoria y con nuestro futuro. Al igual que el vampiro, el cine acumula en su recuerdo y vampiriza el paso de la historia.

Por otra parte, tampoco podemos olvidar el hecho de que en la pantalla grande lo que se nos muestra en la mayoría de las ocasiones son las vidas, sentimientos, recuerdos y comportamientos de personas. Así, podríamos decir que el cine, de la misma manera que Drácula, vampiriza el acervo cultural y social humano.

Es interesante comentar que tanto el personaje de Drácula como su participación en el cine llegaron a vampirizar al propio Bela Lugosi (el intérprete que inmortalizó a Drácula en la gran pantalla). Este actor terminó sus días en un sanatorio, creyéndose él mismo el conde Drácula. De hecho, el propio Lugosi confesó tras el estreno de la película de Tod Browning:

Era víctima de un auténtico hechizo que no me atrevía a romper. Si me salía de mi personaje aunque solo fuera un momento, la inquietante amenaza del terrible conde Drácula desaparecía de la caracterización, y mi poder sobre el público perdía fuerza (Losilla, 1997: 43).

Para ejemplificar esta idea de la vampirización, y muy estrechamente relacionado con la anécdota de Bela Lugosi que acabamos de mencionar, la película de E. Elías Merhge La sombra del Vampiro (Shadow of the Vampire) nos puede resultar de gran utilidad. El argumento de la película es el siguiente. En 1921, Murnau está rodando Nosferatu en la Europa del Este. El director está decidido a hacer la película más auténtica jamás vista. Para este fin Murnau ha contratado a un vampiro auténtico, Max Schreck, como protagonista. Para no alarmar al resto de los miembros del equipo, Murnau explica el peculiar comportamiento de Schreck diciéndoles que es un actor que sigue el método Stanislavsky. En un momento de la película, presenciamos la siguiente conversación entre Greta (la actriz protagonista de Nosferatu) y Murnau (el director):

Murnau: Greta, ¿cómo puede interesarte hacer teatro cuando puedes actuar en una película?

Greta: Porque el público del teatro me da vida mientras que esa cosa (señalando una cámara de cine) simplemente me la quita.

En este breve diálogo, Greta señala intuitivamente la capacidad del aparato cinematográfico para aprehender y guardar momentos, lugares, perso- 
nas y acciones que, sin embargo, pasan e incluso terminan desapareciendo. La capacidad de la imagen cinematográfica para sobrevivir a aquellos que refleja (de los que se nutre, en otras palabra) está en el origen mismo de la afirmación de Greta y del paralelismo que propongo entre el hecho fílmico y el vampirismo.

\section{OSCURIDAD}

A lo largo de las diferentes versiones cinematográficas, se han ofrecido bastantes interpretaciones sobre Drácula y la noche. Existen detalles que cambian considerablemente de una película a otra; pero lo cierto es que, en todas ellas, la luz siempre se presenta como un enemigo del vampiro. En este sentido, resulta bastante ilustrativa la última escena de Nosferatu, de Murnau, en la que el vampiro es destruido y convertido en cenizas al entrar la luz del sol a través de la ventana del cuarto de Mina. En el final de Drácula, de Tod Browning, el conde no consigue culminar la vampirización de Mina al sorprenderle el amanecer, viéndose obligado a retirarse a su ataúd. De una u otra forma, a través de estas películas, se nos ha hecho llegar la idea de que Drácula solo puede funcionar y existir en la oscuridad, en la noche.

En la novela de Bram Stoker, en ningún momento se afirma que la luz del sol pueda destruir a Drácula. De hecho, en la novela, Drácula se aparece en varias ocasiones durante el día. Sin embargo, solamente durante la noche puede hacer un pleno uso de sus poderes sobrenaturales, como la capacidad de metamorfosearse en murciélago o en lobo.

Por otra parte, el contraste entre la luz y la oscuridad, el día y la noche, simbolizan una constante tensión entre el bien y el mal, Dios y el diablo, la pureza y la lujuria, la religión y la herejía, el orden social y el caos. El vampiro se instaura cómodamente en las tinieblas, constituyéndose en el reverso de la religión, la moral, la pureza, etc. valores asociados a la claridad pero que al mismo tiempo nos encorsetan y nos reprimen frente a la libertad, la impudicia y la inmunidad que nos ofrece la tentadora oscuridad.

También el cine nace «esclavizado» a la oscuridad. El anonimato y la morbosa condición de «voyeurs» en la que nos situamos ante la gran pantalla nos convierten hasta cierto punto en vampiros acechantes preparados para asumir vivencias de otras personas. Al mismo tiempo, y paradójicamente, también nos coloca en una delicada situación de víctimas cuyos sentimientos y experiencias son vampirizadas ante la gran pantalla. 
Emilio García y Santiago Sánchez nos recuerdan que, en un tratado sobre óptica, Vitelio afirma que, en la percepción de la belleza y la fealdad, la facultad distintiva puede equivocarse debido a la disposición inadecuada de una serie de circunstancias. La primera de estas circunstancias que menciona Vitelio es «la insuficiencia de la luz» (García, 1985: 20). En este tratado, Vitelio afirma que la contemplación de cualquier objeto en determinadas circunstancias como la oscuridad no solo puede ser decisiva en lo que se refiere a diversos cambios en nuestra percepción visual, sino también en lo concerniente a nuestra «percepción moral», subjetiva, valorativa y ética de todo lo que contemplamos; nuestra apreciación de lo bueno y lo malo, lo feo y lo hermoso, puede verse considerablemente afectada por la oscuridad. Es decir, las tinieblas no son solo una circunstancia física, sino también un estado moral. En esta línea, queremos entender también en un sentido metafórico el hecho de que tanto Drácula como el cine dejen de funcionar con la luz: ambos «mueren» en el momento en el que se intenta racionalizar todo con un criterio positivista y pragmático.

En una escena de la película Shadow of the Vampire, se refleja clarísimamente esta identificación entre el vampiro y el cine en relación con la oscuridad. El personaje de Schreck se queda solo en la sala de proyección y se deleita contemplando en la pantalla blanca la escena de un amanecer. Schreck, que no ve la luz del sol desde hace siglos, permanece fascinado contemplando este amanecer ficticio. En ese momento coloca su mano delante del haz de luz de manera que se proyecta en la pantalla blanca, haciendo hincapié en su carácter cinematográfico inseparable de su existencia «real».

\section{MITO}

Un elemento definitorio en la conformación del cine hasta llegar a nuestros días y convertirse en el arte por excelencia del siglo XX, ha sido su carácter mítico. Este factor también ha jugado un papel importantísimo en la evolución del mito del vampiro; aunque podemos rastrear su existencia en tradiciones ascentrales, lo cierto es que toma su fuerza sobre todo a raíz de la publicación de la novela de Bram Stoker. A partir de ese momento, el mito del vampirismo irá inevitablemente asociado al nombre de Drácula.

Los mecanismos por los cuales se conforman los mitos, en cierta manera, desfiguran algo para hacerlo más atractivo. Esta característica se ha cumplido a la perfección tanto en el caso del cine como en el del vampiro. El 
cinematógrafo, aparato tecnológico, producto de la modernidad y de la sociedad cientificista y utilitarista, acaba trascendiéndose a sí mismo, deformando su propia esencia, para hacerla más atractiva. El cine ya no es solamente el cinematógrafo. Deforma la realidad que nos presenta, los coches, las personas, las calles, deforma sus propios personajes que ya no son actores, son «estrellas», y además, en ocasiones, nos ofrece la imagen en un formato deformante: por ejemplo, el cinemascope. Todo ello para ejercer una mayor fascinación sobre el espectador. De manera que la época dorada de Hollywood, la etapa del cine clásico, se caracteriza principalmente por su carácter mítico, y por el funcionamiento del «star-system».

También se ha producido esta mitificación en lo que al vampiro se refiere; Drácula es, entre otras cosas, una estilización y, por tanto, una deformación de toda la tradición vampírica anterior. El acierto de Bram Stoker consistió en aglutinar en su personaje toda la mitología sobre el vampiro, haciendo de este un ser misterioso, atractivo y repulsivo al mismo tiempo: «He is (... ) like almost all gods of the underworld, a fertility deity, a giver of Life. He is beautiful, powerful, active» (Hallab, 2009: 15). Según Peter Day, lo que distingue a los vampiros de otros monstruos (ya sean de la literatura, el cine o el folklore) es que el vampiro tiene una forma humana reconocible y, en ocasiones, incluso atractiva (Day, 2006: 60).

Por otro lado, es importante señalar el valor sagrado que adquiere el mito. En el caso de Drácula, abundan las connotaciones religiosas de inversión de la liturgia cristiana que conlleva consigo el vampiro que es considerado un anticristo. En lo que se refiere al cine, no cabe duda de que ha creado su propia liturgia pagana, tanto en el culto y adoración a sus estrellas como en las pautas y prácticas que se han establecido para el ritual de su visualización: la oscuridad, el silencio, etc.

Una de las características más significativas de los mitos es su carácter mitad humano mitad divino: «the fascination of the vampire lies in his being both human and supernatural» (Hallab, 2009: 4). Según Mary Hallab, el vampiro es en sí mismo una declaración religiosa. Y eso es debido a sus orígenes sobrenaturales, sus poderes parecidos a los de los dioses y su frecuente identificación con Satán (e incluso algunas veces, Dios). De hecho, nos plantea cuestiones sobre el significado del alma y la existencia del más allá, la existencia de un ser trascendente y sobre la naturaleza del mal: «it carries about with its own mysterious and divine aura that derives from its origins in gods of nature and the underworld» (Hallab, 2009: 14). 
Otra de las características principales del mito es la de su propia imposibilidad objetiva, por un lado, y su carácter subjetivamente verdadero, por otro. Tanto el cine como Drácula cumplen ambos requisitos. Drácula es un ente abstracto cuya existencia es imposible desde un punto de vista racional y objetivo; sin embargo, es algo que a lo largo de la novela deviene totalmente real desde un punto de vista subjetivo. De hecho, el auténtico triunfo de Drácula consiste en conseguir que los demás asuman y reconozcan su existencia. Ese es también el verdadero triunfo del mito. En cuanto al cine, lo que vemos en pantalla se convierte también en subjetivamente verdadero gracias a una deficiencia del nervio óptico y a una predisposición por parte del espectador en lo que se ha dado en llamar un pacto ficcional.

Ni Drácula ni el cine son reales, sino que ambos son un mero reflejo de la realidad. No son la vida misma, pero la transcienden, la superan y van más allá. El vampiro y el cine son el reflejo de algo que ha existido, pero que ya no existe: «Jugando a imitar la verdad con un nuevo arte, transforma en seres las sombras de éstos, y convierte en verdad todas las ficciones» (García, 1985: 19). Drácula, como el cine, consigue que aceptemos su abstracta entidad como una realidad, y producen efectos y despiertan sentimientos en nosotros similares a los de la propia vida.

Otro de los aspectos sobre los que más se ha llamado la atención en lo que a la condición mítica se refiere es el hecho de que los mitos, de una u otra forma, nos hablan siempre de los orígenes del mundo, de los dioses, del hombre, su naturaleza, su origen y su condición, así como el origen de las instituciones religiosas y político-sociales. En el caso del vampiro, todavía produce hoy una fuerte desazón en sus lectores debido a que nos está hablando de los orígenes del hombre, de nuestros dioses, de nuestras creencias y de los valores en los que se asientan nuestras instituciones y nuestra civilización. Nuestros vampiros, como los mitos, ofrecen sentidos, significados y respuestas en esas áreas de la vida que no pueden ser explicadas por sistemas más organizados de ciencia, psicología o religión.

En cuanto a la gran pantalla, es indudable que los grandes clásicos de todos y cada uno de los géneros nos hablan en realidad, independientemente de ambientaciones y tramas argumentales superficiales, de todas esas cuestiones existenciales que han sido siempre de vital importancia para el hombre.

Por otra parte, tanto Drácula como el cine asumen en sí mismos, como parte de su condición mítica y de una manera inseparable, los opuestos: la tesis y su antítesis, los rasgos positivos y los negativos, lo feo y lo bello, el 
bien y el mal, la luz y las tinieblas, dios y el diablo. Drácula, como se ha dicho en repetidas ocasiones, puede ser un símbolo de la maldad, pero también nos ofrece una serie de valores que no son en sí mismos negativos; valores como la libertad, la búsqueda del propio placer, la sensualidad en sus manifestaciones más extremas y sin ningún tipo de represiones y la afirmación del primitivismo y de la parte más intuitiva del hombre dejando a un lado su racionalidad. Además, tenemos que tener en cuenta la insistencia con la que la crítica ha identificado al vampiro con el lado oscuro de la sociedad y de la civilización, con la cara oculta del hombre que se encuentra en una contradicción entre sus deseos más primitivos y animalizados y las obligaciones y restricciones a las que lo somete la civilización. No solamente Drácula es un ser que encarna los valores negativos y diabólicos frente a sus perseguidores, que encarnan los aspectos positivos de la civilización, sino que además el propio vampiro encarna a su vez una serie de necesidad básicas en el ser humano que una sociedad hipócrita y excesivamente preocupada por la apariencia no ha sabido cubrir. El vampiro y lo que este representa es parte indisoluble de la sociedad misma, es decir, el valor opuesto a ésta pero paradójica e inevitablemente, caras de la misma moneda:

La lucha que plantea Drácula entre la luz (Van Helsing, la voz de la ciencia y sus aliados) contra las tinieblas (Drácula, la superstición) va mucho más allá del sempiterno enfrentamiento Bien-Mal de la tradición cristiana y de las moralejas de los cuentos de hadas: por un lado, supone el conflicto del progreso social e histórico con sus fantasmas; por otro, el del individuo con sus propias pesadillas (Díaz, 1997: 94).

Si aplicamos esta oposición de contrarios al cine, podemos apreciar que ya desde los propios argumentos en los que se basa el cine clásico, todo es, en última instancia, una oposición de contrarios. Por ejemplo, en las películas del que ha sido considerado el creador del cine moderno, David W. Griffith, el esquema argumental y la puesta en escena están clarísimamente basados en este juego de oposiciones: interior-exterior, malos-buenos, ricospobres, vida pública-vida privada. Esta dualidad de opuestos siempre presente en el mito es algo que se observa en la propia materialidad del cinematógrafo. Para la proyección de cualquier film es necesaria una casi total oscuridad en la sala, pero lo que realmente posibilita la visión de las imágenes es la luz, la proyección de un haz de luz en la pantalla blanca. Por lo tanto, el cine lleva interiorizado, en las mismas condiciones materiales de su percepción, el juego de opuestos: la luz y la oscuridad. 


\section{ANTÍDOTO CONTRA LA MUERTE}

Tanto Drácula como el cine intentan parar la muerte, eternizar la vida. En su origen, se especuló sobre la posible utilidad del nuevo invento llamado cinematógrafo que, según los propios hermanos Lumière era una invención sin futuro. Uno de los intereses que presentaba este utensilio era el de poder conservar eternamente a los familiares y seres queridos después de muertos. De hecho, este argumento se utilizó como «gancho» publicitario a la hora de atraer público al cine.

Drácula, por su parte, también promete la vida eterna al vampirizar. Sin embargo, el vampiro no solo no concede la vida eterna sino que constituye un obstáculo en ese proceso eterno de relación y continuidad entre la vida y la muerte que nos lleva a la vida eterna. También el cine puede ser en este sentido una obstrucción artificial de lo que supone el proceso natural de la vida y la muerte humanas. Supone una detención del flujo de la vida para congelarlo en el objetivo artístico que es el film. La no-muerte que nos ofrecen tanto el vampiro como el cinematógrafo nos conserva eternamente en una falsa vida y en una falsa juventud.

En este sentido, Drácula se caracteriza por una angustiosa imposibilidad de conciliar materia y espíritu:

... ya que carece de los privilegios del hombre y del espíritu solo tiene sus sufrimientos: por un lado no puede disfrutar de los goces de la vida terrena, pero está sujeto a las ansias de la alimentación, como cualquier ser vivo; por otro, posee cualidades sobrenaturales como muchos espíritus, pero estas quedan mermadas por sus necesidades corporales y, además, puede ser destruido por los mortales, a diferencia de lo que sucede con fantasmas o demonios (Díaz, 1997: 92).

Esta misma tensión entre materia y espíritu se produce, en cierta forma, en el cine. Por una parte, no ha existido un arte de mayor fisicidad (en los cuerpos, los rostros, las calles, los paisajes,...), sin embargo, su esencia no es tan palpable como la de un cuadro, una escultura o una fotografía. Si bien podemos tocar el celuloide, lo cierto es que en el momento de su proyección, se desvanecen su materialidad; solo tenemos un haz de luz que proyecta «fantasmas» en movimiento.

El vampiro señala temas y actitudes sobre la muerte y la inmortalidad que tienen capacidad para apelar al ser humano en todos los tiempos y en todos los lugares. Según Mary Hallab, el vampiro no solamente nos ofrece 
un enfoque mítico sobre la preocupación existencial y universal por la muerte sino que además, aporta una mirada bastante optimista: «the vampire overcomes death and, in doing so, promises eternal life on a somewhat earthier and more comprehensible level than most religious faiths» (Hallab, 2009: 6).

Los vampiros ayudan a tender un puente en la grieta que se abre entre la vida y la muerte, reafirmándonos en la idea de que la muerte es parte integral de la vida. De hecho, el vampiro aporta una especie de «gloria» a la muerte que la rescata del anonimato y la desgracia en la que ha caído en el mundo moderno (Hallab, 2009: 15).

Esta obsesión por «permanecer» de alguna manera después de la muerte se ve muy bien reflejada en una escena de la película Shadow of the Vampire, en la que tiene lugar la siguiente conversación en la que Murnau (el director de Nosferatu) le explica Albin Grau (el productor) que Schreck, el protagonista de la película, es un vampiro de verdad:

Murnau: Cuando vine para localizar exteriores, lo encontré a él. Vivía en un antiguo monasterio.

Albin: ¿Qué fue exactamente lo que le propusiste?

Murnau: Que interpretara a un actor que interpretaba a un vampiro.

Albin: ¿Por qué? ¿Qué le ofreciste a cambio?

Murnau: Le ofrecí la vida eterna... y a Greta...

Albin: ¿A Greta? ¡No tenías ningún derecho!

Murnau: Lo hice por la ciencia y para que pasara a la posteridad.

No deja de resultar paradójico el ofrecerle a un vampiro la inmortalidad. Esto demuestra que el tipo de inmortalidad que ofrece el cine transciende el mero hecho de la muerte física y consiste en la continuidad de una forma intacta y sublimada. El siguiente discurso del personaje de Murnau en la película Shadow of the Vampire ejemplifica a la perfección esto de lo que venimos hablando:

Nuestro propósito, nuestra lucha es crear arte; nuestra arma, la imagen en movimiento. $Y$ puesto que es una imagen en movimiento podemos acercarla o alejarla a nuestro antojo, convertirla en poesía mediante sombras que se alargan y se ocultan; iluminarla de modo que la luz esculpa los rostros ya reflejen alegría o agonicen y envolverla en una música que perdurará para siempre porque tendrá un contexto tan cierto como segura es la muerte. Somos científicos comprometidos con la creación de memoria; pero nuestra memoria no se enturbiará ni se desvanecerá. 
En estas palabras, Murnau se hace eco de un hecho que en los años 20 quizá solo se podía intuir, esto es, que el cine iba a crear una suerte de panteón mitológico que aseguraría un tipo de inmortalidad distinta a la de otras artes. Este modelo de inmortalidad viene dado por la posibilidad de reconectar en imágenes parlantes y en movimiento que recogen «fielmente» cómo seres desaparecidos hablaban y se movían. El ser representado ha muerto y sin embargo sigue «vivo», actuando e interactuando en el celuloide. Como sucede con el vampiro, esta dimensión de la vida es distinta y no puede ser equiparada de ninguna forma con una muerte absoluta y final.

\section{CARÁCTER COLECTIVO}

En nuestra opinión, es enormemente importante el carácter colectivo del que se revisten todas las acciones de Drácula, así como la visualización de cualquier film.

Por una parte, está el cine que no puede prescindir de su público. La visualización del film es un proceso tradicionalmente comunitario, produciendo un efecto de catarsis colectiva. Se visualiza el film de un modo individual, aislados los unos de los otros, pero eso sí, siempre en colectividad. Es lo que se ha dado en llamar la soledad acompañada del cine. Así el estado hipnótico que produce el cine cobra su sentido cuando surge efecto en una comunidad.

Por otra parte, está Drácula y sus efectos en cadena de vampirización colectiva. Hay en la novela un elemento importantísimo que muchas de las adaptaciones cinematográficas han pasado por alto: se trata de la epidemia de peste que provoca la llegada de Drácula a Inglaterra:

También es muy corriente la idea del contagio (la víctima del vampiro se convierte a su vez en vampiro) y la asociación de esta criatura con plagas y enfermedades: en varias leyendas medievales anglosajonas el causante de una epidemia de peste es un vampiro (Díaz, 1997: 17).

Además, está el personaje histórico en el que se inspira el mito de Drácula: el príncipe Vlad Tepes fue un guerrero cruel que utilizó métodos despiadados en sus luchas, métodos que han llegado a nosotros a través de documentos y de la propia tradición oral. Algunas de las tácticas bélicas que empleaba eran las llamadas guerras bacteriológicas, utilizando a afectados 
de lepra, sífilis o peste bubónica que se disfrazaban y se infiltraban en los campos enemigos para contaminarlos.

Otro aspecto del vampirismo relacionado con la colectividad es su conexión con las enfermedades venéreas: «la idea del vampirismo como una plaga que se propaga a sus víctimas y hace de éstas portadoras de la enfermedad y nuevos agentes de contagio, tal y como ocurre en las enfermedades venéreas» (Díaz, 1997: 70).

Esta idea del vampiro como propagador ya sea de enfermedades materiales o espirituales, hace que los afectados no sean únicamente sus víctimas directas sino todos los que les rodean: «los actos del vampiro resuenan en un entramado social y lo corrompen» (Díaz, 199). Parece, pues, que el vampirismo es algo que, de una u otra forma, aparece concebido como una «enfermedad» contagiosa que afecta siempre a comunidades enteras: «vampirism can be understood as a kind of viral infection, possibly like AIDS» (Gordon, 1997: 19).

De hecho, en la novela de Stoker, uno de los aspectos que más atrae a Drácula de Londres es la posibilidad de perderse en la muchedumbre de la ciudad. Drácula informa a Jonathan Harker al que ha contratado para que le facilite su viaje a Londres, que su único deseo es mezclarse con los ciudadanos de la comunidad: «I long to go through the crowded streets of your mighty London, to be in the midst of the whirl of humanity, to share its life, its change, its death, an all that makes it what it is» (Stoker, 2003: 20).

De hecho, como afirma Mary Hallab, los vampiros son seres enormemente enraizados en una determinada comunidad: «Vampires are people, citizens of a community, who, usually, as the result of some failure in the complicated rituals surrounding burial and death, did not die but became living dead» (Hallab, 2009: 12).

Para esta autora, la existencia del vampiro refuerza el sentido de identidad comunitaria y de continuidad histórica con el pasado. De hecho, el vampiro de la tradición folklórica suele ser un antepasado o familiar nomuerto que insiste en mantener relaciones, normalmente no deseadas, con los vivos. Por su parte, en la literatura moderna, el vampiro personifica el pasado no tan muerto, insistiendo en la interconexión de nuestros orígenes con lo que ahora somos. Como un ser vivo representante de la historia, el vampiro nos dice que, en este caminar en la historia, no estamos solos, que ni nuestro pasado ni nuestros muertos han desaparecido totalmente. 


\section{VIAJE EN EL TIEMPO Y EN EL ESPACIO}

Otra de las concomitancias entre Drácula y el cine es su capacidad para viajar en el tiempo y en el espacio. En lo referente al tiempo es obvio que el cine es un instrumento capaz de hacer que en dos horas de duración recorramos toda la historia de la humanidad. A través del cine podemos lograr lo materialmente imposible, por ejemplo ver cómo las personas envejecen para posteriormente volver a verlas en su juventud, a través del montaje, la cámara lenta, cámara rápida, etc. Eso es lo que hace el conde durante su viaje a Inglaterra. Jonathan Harker abre el ataúd de Drácula y contempla admirado cómo milagrosamente ha rejuvenecido bastantes años en su aspecto. Por otra parte, el conde a lo largo de sus conversaciones con Jonathan Harker en Transilvania, deja entrever que su existencia se remonta a tiempos medievales. Así a través de los siglos, el vampiro desafía el paso del tiempo encarnando el colapso moderno del tiempo, del espacio y las comunicaciones (Abbott, 2007: 57).

Por su parte, el cine como una máquina de viajar en el tiempo y en el espacio, nos lleva a lugares en los que nunca hemos estado físicamente. En una misma película podemos recorrer distintos lugares lejanos entre sí, incluso podemos movernos en el terreno de lo fantástico y visitar lugares que no han existido y que nunca existirán.

En la novela de Bram Stoker podemos comprobar cómo Drácula también es capaz de desplazarse en el espacio (aunque con mayor dificultad). Viaja, por ejemplo, de Transilvania hasta Inglaterra. Por otra parte, la entrada en su castillo supone un viaje hacia lo imposible y lo fantástico. Su castillo situado en Transilvania, a pesar de la veracidad con la que Stoker describe los paisajes, es el terreno de la no-realidad. De cualquier forma, no podemos olvidar que en lo que se refiere a la movilidad espacial del vampiro, existen, como ya hemos apuntado, ciertas dificultades. Su desplazamiento espacial debe hacerse ayudado de medios externos, como barcos, personas que transporten las cajas llenas de tierra, etc. Además también queda bastante claro que Drácula si bien puede viajar, no puede separarse de su tierra natal, de manera que debe llevar consigo una serie de cajas llenas de tierra de Transilvania para poder descansar en ella. En cierta forma, podríamos afirmar que el vampiro, a pesar de la movilidad espacial de la que hemos hablado, no se mueve. Este hecho, en nuestra opinión, está estrechamente relacionado con la aparente movilidad del cine que, sin embargo, está completamente condicionado por sus necesidades materiales: necesita un proyector y una sala acondicionada. Así, pues, el cine nos hace viajar, pero 
al mismo tiempo queda anclado y nos ancla a un espacio físico muy determinado.

Por otra parte, en su novela, Stoker insiste en el transporte moderno para enfatizar la percepción del espacio como algo unificado e interconectado. De hecho sus personajes están continuamente navegando por el espacio urbano. Según Stacey Abbot, es el viaje en tren lo que supone un mayor cambio en la percepción del paisaje en el siglo XIX. Abbot sugiere que la transición del carruaje al tren lleva al desarrollo de una nueva percepción espacio temporal:

The train travel through the landscape caused the views from the window to become blurred and indistinct. The modern traveler, however, began to recognize that this speed served to shrink space and bring various elements form different locations together in the same frame, creating a new way of seeing the world (Abbott, 2007: 20).

Los personajes de Stoker están en el centro de esta compleja red de transportes que une toda la ciudad. Incluso hay una escena en la que Jonathan Harker encuentra e Drácula tumbado en el sofá de su biblioteca en Transilvania estudiando los horarios del tren. El vampiro ha sufrido un proceso de liberación de las fronteras de espacio, tiempo y cuerpo y, como resultado, encarna el legado de las transformaciones de la modernidad. Stacey Abbott afirma que la habilidad para experimentar muchos acontecimientos distantes al mismo tiempo que se hizo posible gracias a las nuevas tecnologías fue parte de un cambio drástico en la experiencia del presente a principios del siglo XX. El presente ya no se percibía como una secuencia de eventos individuales y locales, sino como una simultaneidad de eventos múltiples y distantes, manifestados en el desarrollo de las nuevas tecnologías incluidos el teléfono, las telecomunicaciones y el cine. Con el desarrollo del montaje paralelo, el cine pudo visualizar una cultura que, a través de la tecnología, experimenta con el presente simultáneo e interconectado (Abbott, 2007: 55).

\section{MISOGINIA}

Tanto en el mito de Drácula como en la evolución argumental e industrial del cine clásico, ha sido decisivo el papel jugado por la figura de la mujer. La fascinación que en uno y otro caso existe por la mujer como objeto de deseo, ha derivado en una inevitable misoginia. El papel de la mujer 
ha sido decisivo en la formación de géneros tan importantes para el cine clásico como el género negro:

....sin misoginia no hay mujeres fatales, héroes existenciales, vampiresas envueltas en boas de plumas, lobos esteparios que investigan casos de mala muerte por un puñado de dólares, piernas torneadas con medias de costura, rictus de amargura y desprecio pegados en el extremos de la colilla, ironía de triple filo en esos diálogos del cliché y chicle de menta entre la bella y el bestia con licencia caducada para investigar. No hay ni erotismo insatisfecho, ni romanticismo duro de la era de la depresión, ni tan siquiera dialéctica hegeliana del ganador/perdedor. Toda esa épica que sigue fascinando la mirada al cabo de las décadas y de las generaciones, es producto directo de la bioquímica misógina del héroe del género negro (Cueto, 1985: 44-45).

La presencia de la mujer ha sido definitiva en la conformación de uno de los géneros más importantes del cine clásico. Sin embargo, su importancia no se circunscribe solamente al cine negro. Incluso en géneros eminentemente masculinos como el western o el cine bélico, uno de los ejes fundamentales radica en la percepción de las distintas figuras femeninas. De hecho, la esencia de la estrella de Hollywood está mucho más simbolizada en la figura de una mujer que en la de un hombre.

En cuanto a la presencia de la mujer en la novela de Bram Stoker, es importantísimo recordar que Drácula solo llega a vampirizar a mujeres: Lucy y Mina. El resto de las víctimas de Drácula que aparecen en la novela son asesinadas por éste, pero en ningún momento se especifica que sean vampirizados, es decir, que se les conceda una supuesta vida eterna. El paso de víctima a vampiro, solo se produce en mujeres. La obsesión por la mujer es bastante obvia en esta novela. La mujer es el pilar de la sociedad porque es el principal eje de un determinado status quo social y familiar; si esta falla, el orden social y moral empieza a desmoronarse. De hecho, cuando Drácula se ve acorralado por sus enemigos, les amenaza con arrebatarles a sus mujeres: "Your girls that you all love are mine already; and through them you and others shall yet be mine-my creatures, to do my bidding and to be my jackals when I want to feed» (Stoker, 2003: 527).

De hecho, según Abbott, una vez que Mina ha sido contaminada por la sangre de Drácula, los hombres deben salvarla para preservar su propio ideal de la mujer como una figura asexual de adoración (Abbott, 2007: 27). Mina es descrita por Van Helsing como: «one of God's women fashioned by 
His own hand to show us men and other women that there is a heaven where we can enter, ant that its light can be here on earth» (Stoker, 2003: 188).

La mujer es el ser que da la vida, de ahí que Drácula las elija para alimentarse. Tampoco podemos olvidar que la única compañía que tiene Drácula en su castillo de Transilvania es femenina: las tres vampiresas que habitan con el conde. En cuanto a estas tres vampiresas que viven con Drácula, podría alegarse que son mujeres activas y sexualmente agresivas. Sin embargo, Joan Gordon las califica como «proper Victorian ladies, remaining properly at home while the master of the house goes forth to do solitary battle against the forces of virtue» (Gordon, 1997: 19).

Las mujeres son el medio de llegar hasta los hombres o, mejor dicho, las mujeres son el medio de llegar hasta el corazón mismo de la sociedad y dañarlo. Una vez vampirizadas, todas las víctimas femeninas pasan a ser, independientemente de cuál fuera su carácter con anterioridad, voluptuosas y agresivas sexualmente. Como las mujeres del cine negro, toman la iniciativa y ejercen una atracción irresistible en los hombres que les llevará a la perdición. No resulta, pues, extraño que a la «femme fatale» del cine se la haya denominado también «vampiresa».

Es posible rastrear toda esta fobia por lo femenino en la novela de Stoker. La mujer aparece reflejada como el objeto del deseo que despierta los más bajos instintos del hombre y le lleva inevitablemente a la degradación. Una concepción de la mujer muy típica, por otra parte, de la doble moral característica de la época victoriana. Gordon habla de los personajes femeninos en la novela de Drácula como «prizes in the contest between males vampire and his male human opponents» (Gordon, 1997: 209).

En este contexto, el vampirismo como metáfora epistemológica del cine apunta a una forma común de concebir la representación falocéntrica e hipersexualizada del sujeto femenino por parte de los géneros tradicionales del cine. Probablemente, una de las reflexiones críticas más importantes sobre este tema sea el ensayo fundacional de Laura Mulvey en el que expone lo siguiente: «The man controls the film phantasy and also emerges as the representative of power in a further sense: as the bearer of the look of the spectator» (Mulvey, 1975: 10). En este sentido, y tal como hemos argumentado en este apartado, Drácula y su mirada sobre el cuerpo femenino, usualmente dócil y concebido como fuente de placer y vida, realmente funciona como un soporte vicario para una mirada espectatorial con una marca genérico-sexual bastante obvia. De hecho, siguiendo a Mulvey y Eco, podríamos concluir que el vampiro ejerce, de forma 
paradigmática, su función de metáfora epistemológica de todo un modelo cinematográfico que tradicionalmente cosifica el ente femenino para el placer de una mirada masculina.

\section{INNOVACIONES TÉCNICAS}

El cine y Drácula no solo nacen al mismo tiempo (la primera proyección pública tuvo lugar en diciembre de 1895 y la novela de Bram Stoker se publicó en 1897), sino que además ambos hacen uso de las innovaciones técnicas de su tiempo.

El cine antes que cualquier otra cosa fue una máquina. El cinematógrafo fue una acumulación de todos los avances de su tiempo en el arte de la fotografía y la luz para poner las imágenes en movimiento. Pero además, el Séptimo Arte ha actuado a su vez como un reflejo y proyección de otros inventos, otros avances tecnológicos:

[...] siempre hay una máquina tras los grandes acontecimientos cinematográficos: el tren de los Lumière inaugura la vía realista, el cohete del Viaje a la luna de Meliès señala con precisión el fecundo cambio de la fantasía, el acorazado de Eisenstein instaura la acerada dictadura del montaje-rey, la cadena de montaje de Tiempos modernos de Chaplin descubre para el invento las posibilidades poéticas y críticas, el robot femenino de Metrópolis instituye la ciencia-ficción con todos los honores y horrores, la cámara y la locomotora de Keaton fundan el arte grande del gag, en aquellos laboratorios barrocamente mecanizados de Caligari, Mabuse, Jekyll, Frankenstein y demás sabios locos se construye el primer terror químicamente puro, el Colt 45 de Gary Cooper y el Winchester 73 de John Wayne señalan el apogeo de la épica irrepetible de western, la moto salvaje de Marlon Brandon proclama el ruidoso advenimiento de la juventud rebelde sin causa de los sesenta, el taxi de Robert de Niro se erige en símbolo amarillo de la era de la violencia callejera, solitaria y mitómana de los duros setenta, y la computadora HALL-9000 de Stanley Kubrick, está en el origen freudiano del intenso tráfico por las galaxias y la cibernética que el cine se trae en esta década de los ochenta (Cueto, 1985: 84-85).

No cabe duda de que la narración cinematográfica ha mantenido siempre relaciones estrechas y continuadas con la tecnología de su tiempo, hasta tal punto que sería posible narrar la historia de las máquinas del hombre a través del cinematógrafo, además de las máquinas futuribles o fantásticas que el propio cine ha inventado. 
Por su parte, en la novela de Stoker se hace alusión a numerosas innovaciones técnicas del momento: el tren, el barco de vapor, la taquigrafía, la mecanografía, el fonógrafo, las transfusiones de sangre, la cámara fotográfica Kodak, los rifles Winchester, etc. Bram Stoker trata de ofrecer un contraste entre un mito tan arcaico como el del vampiro y la Inglaterra del momento en el que se escribe la obra, entonces la cuna de un mundo civilizado y una sociedad cada vez más fascinada por los avances tecnológicos. Es interesante cómo Drácula, a pesar de vivir aislado de todos estos cambios y vivir en una suerte de «tiempo congelado», no puede evitar depender, hasta cierto punto, de estos avances. De hecho, la victoria que consiguen sus perseguidores sobre él, se debe, entre otros factores, al hecho de que Drácula no quiera utilizar el barco de vapor y en su lugar se transporte en velero, y que en lugar de viajar en ferrocarril, prefiera transportar sus cajas de tierra en carretas de gitanos.

Stoker sitúa la acción de Drácula en su Londres contemporáneo que aparece lleno de iconos de la vida moderna. En el tiempo en el que Stoker escribió su novela, Londres estaba sufriendo un crecimiento masivo. No solamente hubo un crecimiento de la población, sino también una mejora del sistema ferroviario y de transporte subterráneo. Según Abbot, en lugar de establecer una oposición estructural entre el vampiro premoderno y la nueva comunidad científica, la novela sitúa el conflicto y al vampiro en el ojo del huracán de un cambio social y tecnológico que enfatiza la ambigua distinción entre los dos. El vampiro pasa a encarnar las relaciones cada vez más ambiguas entre la ciencia y el oscurantismo. Estas relaciones simbolizadas por el choque entre el vampiro y los cazadores del vampiro en la novela, más que sugerir una oposición entre lo primitivo y lo civilizado, es realmente un choque entre distintas modernidades: una nueva forma de modernidad (el mundo hipermoderno de la electricidad, la hipnosis, la telepatía, las telecomunicaciones y la desintegración del espacio y del tiempo) está gradualmente derribando las formas de modernidad ejemplificadas por el pensamiento racional y el análisis científico (Abbott, 2007: 16-17).

Las nuevas tecnologías anularon la distancia y facilitaron la comunicación a través de fronteras espaciales, temporales e incluso espirituales. El potencial para más usos sobrenaturales de estas tecnologías, aumentó durante este periodo de cambio. El siglo XIX fue testigo de esta revolución entre el positivismo y unos nuevos paradigmas de ciencia impulsados por la explosión del desarrollo en las telecomunicaciones, las ciencias eléctricas e investigaciones en el campo de la física: 
This dependence upon the material and observable was undermined by the evolution in the nineteenth and early-twentieth centuries of sciences that relied upon unseen transmissions, invisible sounds and light weaves, and electrical impulses and currents. Although positivism did seek to reconcile these startling innovations within its areas of study, these new technologies suggested new possibilities and unexplored areas in science that could not be explained or contained by positivism (Abbott, 2007: 32).

Bram Stoker explotó las experimentaciones de este periodo, creando un cuento sobrenatural que subvertía el racionalismo y el materialismo y marcaba la ambigüedad entre la ciencia y lo sobrenatural uniendo el mundo extraordinario de los vampiros al dominio siempre cambiante de las ciencias eléctricas y las telecomunicaciones. La novela de Stoker sugiere que lo sobrenatural no solamente es posible, sino que además es un producto natural del mundo moderno. Las nuevas tecnologías minan nuestra percepción de la «normalidad», sugiriendo la posibilidad de nuevas formas de «normalidad». Así en el Drácula de Tod Browning, el personaje de Van Helsing afirma: «Las supersticiones de ayer se han convertido en los hechos científicos de hoy en día».

Todas las características de Drácula: su naturaleza etérea, su encarnación del electromagnetismo, su habilidad para transformarse, su uso de la telepatía y la hipnosis son producto de la revisión que en el siglo XIX están sufriendo las ciencias y lo sobrenatural y sugiere la entrada del estudio científico en un nuevo periodo en el que todos los sistemas de creencias y pensamientos están siento desafiados por lo desconocido. Así pues, esta batalla entre Drácula y sus enemigos no es una batalla entre el bien y el mal sino más bien una batalla entre la ciencia normal y la extraordinaria, entre lo conocido y lo desconocido.

\section{CONCLUSIONES}

Este ensayo no es el primero en abordar el tema de las relaciones entre Drácula y el cine. Muchos han sido los críticos que han querido estudiar esta comparación. Así se ha afirmado que Nosferatu, de Murnau, plantea una metáfora del cine al mostrar el triunfo de la luz (que hace nacer las imágenes) sobre las tinieblas. También se ha visto el Drácula, de Francis Ford Coppola, como una metáfora del cine: el cine como el último refugio del desarraigado, donde se pueden congelar las ilusiones. 
En el final de la película Shadow of the Vampire, el personaje de Murnau está rodando la última escena de Nosferatu, en la que el conde Orlok, después de haber vampirizado al personaje de Ellen, se ve sorprendido por el amanecer y muere destruido por la luz del sol. Cuando el vampiro finge morir, se abre una puerta en el plató que deja entrar luz del día que destruye al vampiro auténtico. El director nos muestra esa escena final de la muerte del vampiro real, a través de la cámara de Murnau. En lugar de ver cómo se destruye, o se convierte en polvo, vemos cómo el celuloide con la imagen del vampiro se quema hasta consumirse en la nada más absoluta, reafirmando la relación simbiótica entre el vampiro y el cine.

Gran parte de las concomitancias que existen entre el vampiro y el cine ponen de manifiesto algunas tensiones típicas de la modernidad. Por ejemplo, según Joan Gordon, tanto el cine como el vampiro disuelven fronteras entre lo privado y lo público, el individuo y la sociedad, unas naciones y otras, la vida y la muerte, el amor y el miedo, el poder y el ostracismo, el sadismo y el masoquismo, lo virtual y lo real, el propio cuerpo y el cuerpo ajeno, lo monstruoso y lo humano, los otros y nosotros mismos. De ahí que una de sus funciones sea la de ayudarnos a construir y definir nuestra propia humanidad (Gordon, 1997: 7).

En este sentido, la función del vampiro como metáfora epistemológica del cine, nos ayuda a comprender, percibir y asimilar todas estas contradicciones típicas de la modernidad. Como afirma Umberto Eco:

De ahí la función de un arte abierto como metáfora epistemológica: en un mundo en el cual la discontinuidad de los fenómenos puso en crisis la posibilidad de una imagen unitaria y definitiva, esta sugiere un modo de ver aquello en que se vive, $y$, viéndolo, aceptarlo, integrarlo a la propia sensibilidad. (...) aparece como una especie de esquema trascendental que nos permite comprender nuevos aspectos del mundo (Eco, 1992: 93).

En este ensayo, hemos tratado de demostrar que en la figura de Drácula quedan cifrados varias características epistemológicas y ontológicas del cinematográfico. No es extraño, por lo tanto, que el subgénero vampírico haya servido tan a menudo para meta-reflexiones sobre asuntos como el estatus de la imagen, el poder de la luz, la vida auténtica y la vida como reflejo, entre otros muchos. En resumen, como afirma Eco en la cita anterior, la sensibilidad cinéfila encuentra una suerte de transitividad y continuidad reflexivamente muy productiva en la relación que el fenómeno fílmico y el vampirismo mantienen. 
En su libro Teorías del símbolo, Todorov afirma: «La simbólica transforma el fenómeno en idea, la idea en imagen, y de tal manera que la idea siempre persiste infinitamente activa e inaccesible en la imagen» (Todorov, 2005: 288). Aplicado a nuestro ensayo, podríamos ver el fenómeno en la novela de Bram Stoker, que pasó a transformarse en la idea el vampiro que a su vez se transformó en imagen cinematográfica funcionando incluso como su metáfora epistemológica, y esa imagen cinematográfica persiste, como afirma el personaje de Murnau en la película de Elias Merhige, «envuelta en una música que perdurará para siempre».

\section{REFERENCIAS BIBLIOGRÁFICAS}

ABBOTT, S. (2007). Celluloid Vampires: life after death in the modern world. Austin: University of Texas Press.

CUETO, J. (1985). Exterior noche. Madrid: Júcar.

DÍAZ, C. y CUETO, R. (1997). De Transilvania a Hollywood. Madrid: Nuer.

DAY, P. (2006). Vampires: myths and metaphors of enduring evil. Amsterdam: Rodopi.

ECO, U. (1992). Obra abierta. Roser Berdagué (trad.). Barcelona: PlanetaAgostini.

GARCÍA, E. y SÁNCHEZ, S. (1985). Así nació el cine. Madrid: Cuadernos de Historia 16.

GELDER, K. (1994). Reading the Vampire. London: Routledge.

GORDON, J. y HOLLINGER, V. (1997). Blood Read. Philadelphia: University of Pennsylvania Press.

HALLAB, M. (2009). Vampire God: the allure of the undead in western culture. Albany: State University of New York Press.

LOSILLA, C. (1997). «Drácula y sus intérpretes: el cuerpo que aparece y desaparece». Dirigido 256, 40-47.

MULVEY, L. (1975). «Visual Pleasure and Narrative Cinema». Screen 16.3, 6-18, en https://wiki.brown.edu/confluence/display/MarkTribe/Visual $+P$ leasure +and +Narrative +Cinema (consultado 13/03/2013).

STOKER, B. (2003) Dracula. London: Penguin Classics.

TODOROV, T. (2005). Teorías del símbolo. Francisco Rivera (trad.). Caracas: Monte Ávila Editores. 


\section{REFERENCIAS FILMOGRÁFICAS}

BROWNING, Tod (Director) y Carl Laemmle (Productor) (1931). Dracula. (Cinta de vídeo).

MURNAU, Friedrich Wilhelm (Director) y Albin Grau (Productor) (1922). Nosferatu (DVD).

MERHIGE, Elias (Director) y Nicholas Cage (Productor) (2000). Shadow of the vampire (DVD).

FORD COPPOLA, Francis (Director y Productor) (1992). Dracula (DVD).

Recibido el 21 de marzo de 2013.

Aceptado el 19 de septiembre de 2013. 